\title{
Associated factors for oral health problems in a sample of Saudi cancer patients
}

This article was published in the following Dove Press journal:

Cancer Management and Research

\begin{abstract}
Nagarajkumar Yenugadhati ${ }^{1,2}$
Alhanouf Naji Albalawi ${ }^{3}$

Aisha Taha Qureshey,*

Eiman Taha Qureshey,*

Hamdan Al-Jahdali ${ }^{4}$

Abdul Rahman Jazieh ${ }^{5}$

Anwar E Ahmed ${ }^{1,2}$

'King Abdullah International Medical Research Center (KAIMRC), Ministry of National Guard, Riyadh, Saudi Arabia; ${ }^{2}$ College of Public Health and Health Informatics, King Saud bin Abdulaziz University for Health Sciences, Ministry of National Guard, Riyadh, Saudi Arabia; ${ }^{3}$ Riyadh Elm University, Riyadh, Saudi Arabia; ${ }^{4}$ Department of Medicine, Pulmonary Division-ICU, King Saud bin Abdulaziz University for Health Sciences, Ministry of National Guard, Riyadh, Saudi Arabia; ${ }^{5}$ Department of Oncology, King Abdulaziz Medical City for National Guard, Ministry of National Guard, Riyadh, Saudi Arabia

*These authors contributed equally to this work
\end{abstract}

Correspondence: Nagarajkumar Yenugadhati

College of Public Health and Health Informatics, King Saud bin Abdulaziz University for Health Sciences, Ministry of National Guard, PO Box 22490,

Riyadh I 1426, Saudi Arabia

Tel +966 I | 4295489

Email nagarajkumar.yenugadhati@gmail. com
Purpose: Oral health in cancer patients was known to influence the quality of life. However, the knowledge of possible factors associated with oral health in cancer patients is seriously lacking in Saudi Arabia. In this study, we aimed to determine the burden of adverse oral health in cancer patients and identify the associated factors for oral health problems.

Materials and methods: A cross-sectional study design was used to recruit a total of 375 cancer patients who attended oncology outpatient clinics at King Abdulaziz Medical City Riyadh (KAMC-R) by using a consecutive sampling technique. A self-reporting questionnaire was used to collect the sociodemographic information, clinical symptoms, and lifestyle factors of cancer patients. Furthermore, depression, anxiety, and stress were assessed by using Depression Anxiety and Stress Scale. The authors assessed the oral health complaints based on seven common conditions (bleeding gums, toothache, mouth ulcers, bruxism, xerostomia, problems affecting speech, and satisfactory dietary intake). Unadjusted and adjusted risk ratios (aRR) and $95 \%$ CIs for the factors associated with the number of oral complaints experienced were computed using Poisson regression model.

Results: The prevalence of oral health conditions experienced by cancer patients was $86.1 \%$ (95\% CI: 82.2\%-89.5\%). Female sex (aRR=1.37, 95\% CI: 1.05-1.78), low income (aRR=1.58, 95\% CI: $1.23-2.04)$, smoking ( $\mathrm{aRR}=1.29,95 \% \mathrm{CI}: 1.02-1.64)$, anxiety (aRR $=1.75,95 \% \mathrm{CI}$ : 1.36-2.24), and stress ( $\mathrm{aRR}=1.25,95 \% \mathrm{CI}: 1.00-1.55)$ were associated with increased risk of oral health problems in cancer patients $(p \leq 0.05)$, whereas breast cancer patients experienced reduced risk (aRR $=0.72,95 \% \mathrm{CI}: 0.56-0.93)$.

Conclusion: Our study highlighted the significant burden of oral health problems in Saudi cancer patients at KAMC-R and identified several key associated factors for oral health to aid healthcare practitioners in improving cancer management practices.

Keywords: oral health, cancer survivors, prevalence, associated factors

\section{Introduction}

Cancer is one of the major public health and healthcare system challenges worldwide that is reaching pandemic proportions. ${ }^{1}$ In 2012, 14.1 million incident cancer cases were diagnosed and 8.2 million deaths were attributed to cancer worldwide. ${ }^{2}$ Incidentally, the burden of cancer is also increasing in Saudi Arabia reaching a total of 15,807 new cases reported in the year $2014^{3}$ and potentially affecting the quality of life of patients. ${ }^{4}$

Although the diagnostic and therapeutic advancements in cancer management were largely beneficial, they have the potential to impact the entire human body and can have a major impact on oral health. ${ }^{5}$ Previous studies found several oral complications in cancer patients, including oral mucositis (OM), dental caries, xerostomia (dryness 
of mouth), osteoradionecrosis, oropharyngeal candidiasis, ulcerations, difficulty in swallowing (dysphagia), neurosensory taste disturbances (dysgeusia), limited mouth opening (trismus), periodontal diseases and tooth mobility, and halitosis; these oral complications could be acute or chronic and might arise during or after cancer treatment. ${ }^{5-7}$ Therefore, disregarding oral health in cancer patients would affect the quality of life with potential implications on morbidity and mortality. ${ }^{5,8}$ The wide range of incidence of OM (10\%-100\%) reported in the literature reveal varied therapeutic susceptibility among cancer patients. ${ }^{9-11}$ Furthermore, the reduced salivary flow reported in cancer patients increases the risk of oral infections and susceptibility to dental caries, which would consequently affect the daily functions and induce problems such as difficulties in speech, chewing, and swallowing to the detriment of quality of life. ${ }^{12-14}$

It is noteworthy that physicians tend to prioritize lifethreatening conditions and neglect oral health in cancer patients. ${ }^{15,16}$ Oral health assessment and treatment should be an integral part of cancer patient management practices to maintain good oral hygiene. Subsequent preservation of daily functions and prevention of infectious diseases would aid in achieving a better quality of life in cancer patients. To the best of our knowledge, no prior research was conducted in Saudi Arabia to evaluate the existence of oral health conditions in cancer patients and their associated factors. Our study would address this important gap in the literature by determining the burden of oral health conditions (by estimating their prevalence) in adult Saudi population and also identifying the common factors associated with oral health conditions experienced by patients attending the oncology outpatient clinics at King Abdulaziz Medical City - Riyadh (KAMC-R), Saudi Arabia. The findings from our research could potentially aid in informing patients as well as healthcare providers (eg, interns, dentists, and oncologists) in improving the assessment and management practices of cancer patients.

\section{Materials and methods}

An observational cross-sectional study design was used to determine the prevalence and common associated factors for oral health conditions experienced by adult cancer patients aged $\geq 18$ years visiting oncology outpatient clinics at KAMC-R between April 2017 and August 2017. KAMC-R is one of the biggest tertiary hospitals in Saudi Arabia and the Middle East with an Oncology Department, providing comprehensive cancer treatment and care to thousands of patients each year. The hospital serves the population of the
National Guard and their dependents, in addition to patient referrals from all over the kingdom and the Gulf region.

The study population, specifically, included both male and female adult cancer survivors, aged $\geq 18$ years, who had no evident cognitive impairment and agreed to enroll in the study. Both Saudis and non-Saudis were included. Patients receiving palliative care and those diagnosed with head and neck cancers were excluded from the study population. A written informed consent was obtained from all the participants. Our study received scientific and ethics approval from Institutional Review Board office at King Abdullah International Medical Research Center (KAIMRC), Riyadh (\# RC16/213/R).

\section{Sample size and sampling strategy}

The sample size was estimated based on $95 \%$ confidence level and a precision of 5\%. The expected prevalence used in the sample size calculations was derived from a systematic review performed in $2010,{ }^{7}$ which reported an overall prevalence of dental diseases to be $28.1 \%$ in cancer patients undergoing therapy. Using the formula for single proportion estimation, a total sample of 311 cancer patients was recommended for this study. The study has $81 \%$ power to detect the expected effect size.

A consecutive sampling method was employed to recruit patients with different types of cancer who fulfilled aforementioned inclusion and exclusion criteria and attended oncology outpatient clinics at KAMC-R, during the study period. A total of 375 cancer patients $(75 \%)$ agreed to participate in our study among 500 eligible patients who were approached for recruitment.

\section{Self-reported questionnaire}

A self-reported questionnaire was used to collect the information on patient's sociodemographic and lifestyle characteristics, such as age, gender, education status, income levels, marital status, family support, smoking, and physical exercise. Patients also reported whether they experienced any of the following seven oral health conditions during a period of 6 months - bleeding gums, dental pain (toothache), mouth ulcers, bruxism (teeth grinding), xerostomia (dryness of oral cavity), problems affecting speech, and satisfactory dietary intake. In addition, information on cancer type, cancer stage, and type of treatment received, number of tumors, time elapsed since cancer diagnosis, information on comorbid chronic disease other than cancer, health insurance coverage, receipt of any form of oral health education, self-declared physical activity (yes vs no), and oral hygiene 
habits (frequent tooth brushing for two or more times per day and use of dental floss) was also collected. Furthermore, we assessed stress, depression, and anxiety in cancer patients using Depression Anxiety and Stress Scale. ${ }^{17}$ Face validity of our study questionnaire was established. The construct validity of our questionnaire about oral health was good as all the items of oral health contributed to a single construct with factor loadings ranging from 0.33 for xerostomia to 0.64 for mouth ulcers.

Questionnaire responses were used to construct categorical variables with meaningful categories that have sufficient sample. If patients were diagnosed with cancer within a year prior to study enrolment, they were defined as newly diagnosed patients. Patients were classified as depressed, anxious, and stressed out if they scored more than 4, 3, and 7 on their respective scales. Further details of the categories of all the variables could be found in the "Results" section.

\section{Oral health status}

The outcome of interest, oral health status, was defined based on a count variable that represented number of oral health conditions experienced by cancer patients. The overall reliability of this oral health measure was determined to be good (Cronbach's coefficient alpha=0.67).

\section{Statistical analysis}

All statistical tests were performed with SAS software version 9.4 (SAS Institute Inc., Cary, NC, USA). Descriptive data for categorical variables were reported as frequency counts and percentages $(\%)$. The means and SD were reported for continuous variables. The prevalence of oral health status was summarized as percentage based on patients experiencing at least one of the seven oral health conditions, and $95 \%$ CIs for proportions were constructed using Clopper-Pearson exact tests. Poisson regression analyses were used to identify the factors associated with number of oral health conditions experienced by cancer patients. The unadjusted (uRR) and adjusted risk ratios (aRR) and their respective 95\% CIs and two-tailed $p$-values were reported for all the variables analyzed using both univariate and multivariate Poisson regression models, respectively. Multi-collinearity was assessed using condition indices and eigenvalues. The goodness-of-fit of the Poisson regression model was assessed using Pearson chi-square test; a nonsignificant test indicates that there was no issue of overdispersion and Poisson regression is suitable for the analysis. Graphical illustrations were used to compare the expected mean number of oral health complaints by different types of cancers. Patients for whom information of the covariate in the model is unknown or missing were deleted from the analysis. A two-tailed $p$-value of $\leq 0.05$ was considered statistically significant.

\section{Results}

A total of 375 cancer patients were recruited in our study, and our analyses were based on 283 patients who had information on all the covariates in the multivariate model. The prevalence of cancer patients experiencing at least one oral health condition was $86.1 \%$ (95\% CI: 82.2\%-89.5\%). Xerostomia $(66.7 \%)$, dental pain (44\%), and bleeding gums $(36.8 \%)$ were the most common oral health complaints reported by cancer patients.

The mean age and SD of cancer patients were 51.8 years and 14.7 years, respectively. Table 1 provides the descriptive statistics as frequencies and percentages for various characteristics of study population. Briefly, majority of patients were female, married, and had either secondary or less than secondary education. About $37 \%$ of the patients belonged to extremely low economic status that earned $<5,000$ Saudi riyals per month. The study sample predominantly comprised of patients suffering from colon and breast cancer, about half the subjects had single tumors. Incidentally, $65 \%$ of cancer patients were newly diagnosed patients who were diagnosed during a period of 1 year prior to enrollment into this study. An overwhelming majority of patients underwent chemotherapy followed by other treatment modalities, including immunotherapy, radiation therapy, and surgery. It is noteworthy that majority of the cancer patients were anxious, and $>40 \%$ were either depressed or stressed out.

The uRR and aRR including their 95\% CIs for the association between number of oral health conditions experienced by the cancer patients and various patient characteristics were reported in Table 2. The oral health complaints experienced by women are 1.4-fold higher than the complaints reported by men $(\mathrm{aRR}=1.37,95 \% \mathrm{CI}: 1.05-1.78)$. In addition, people who were smokers $(\mathrm{aRR}=1.29,95 \% \mathrm{CI}: 1.02-1.64)$ and family income $<5,000$ Saudi riyals per month $(\mathrm{aRR}=1.58$, 95\% CI: 1.23-2.04) were associated with increased risk of experiencing adverse oral health conditions. It is noteworthy that the expected number of oral health complaints was significantly lower among breast cancer patients compared with patients suffering from colon cancer $(\mathrm{aRR}=0.72,95 \%$ CI: 0.56-0.93); no significant differences were observed with other cancer types. The expected number of oral health conditions experienced by cancer patients was high among those suffering from anxiety $(\mathrm{aRR}=1.75,95 \% \mathrm{CI}$ : $1.36-2.24)$ and stress $(\mathrm{aRR}=1.25,95 \% \mathrm{CI}: 1.00-1.55)$ compared with 
Table I Descriptive statistics of study population

\begin{tabular}{|c|c|c|c|}
\hline Patient characteristics & Category & Number of patients $(n=375)$ & Percent \\
\hline \multirow[t]{3}{*}{$\mathrm{Age}^{\mathrm{a}}$} & Mean & 51.8 years & - \\
\hline & SD & 14.7 years & - \\
\hline & Median & 52 years & - \\
\hline \multirow[t]{3}{*}{ Gender } & Female & 216 & 57.6 \\
\hline & Male & 154 & $4 I .1$ \\
\hline & Missing & 5 & 1.3 \\
\hline \multirow[t]{3}{*}{ Marital status } & Married & 289 & 77.1 \\
\hline & Not married & 82 & 21.9 \\
\hline & Missing & 4 & I.I \\
\hline \multirow[t]{3}{*}{ Education status } & Secondary or less & 262 & 69.9 \\
\hline & University or higher & 95 & 25.3 \\
\hline & Missing & 18 & 4.8 \\
\hline \multirow[t]{4}{*}{ Family income } & $<5,000$ & 139 & 37.1 \\
\hline & $5,000-10,000$ & 122 & 32.5 \\
\hline & $\geq 1 \mathrm{I}, 000$ & 97 & 25.9 \\
\hline & Missing & 17 & 4.5 \\
\hline \multirow[t]{2}{*}{ Smoking status } & Yes & 98 & 26.1 \\
\hline & No & 277 & 73.9 \\
\hline \multirow[t]{6}{*}{ Type of cancer } & Breast cancer & 125 & 33.3 \\
\hline & Lung cancer & 35 & 9.3 \\
\hline & Leukemia & 17 & 4.5 \\
\hline & Lymph node & 18 & 4.8 \\
\hline & Colon cancer & 170 & 45.3 \\
\hline & Missing & 10 & 2.7 \\
\hline \multirow[t]{3}{*}{ Number of tumors } & Single tumor & 182 & 48.5 \\
\hline & Two or more & 165 & 44.0 \\
\hline & Missing & 28 & 7.5 \\
\hline \multirow[t]{3}{*}{ Surgical therapy } & Yes & 211 & 56.3 \\
\hline & No & 163 & 43.5 \\
\hline & Missing & 1 & 0.3 \\
\hline \multirow[t]{3}{*}{ Chemotherapy } & Yes & 310 & 82.7 \\
\hline & No & 61 & 16.3 \\
\hline & Missing & 4 & I.I \\
\hline \multirow[t]{3}{*}{ Radiation therapy } & Yes & 177 & 47.2 \\
\hline & No & 194 & 51.7 \\
\hline & Missing & 4 & 1.1 \\
\hline \multirow[t]{3}{*}{ Immunotherapy } & Yes & 226 & 60.3 \\
\hline & No & 143 & 38.1 \\
\hline & Missing & 6 & 1.6 \\
\hline \multirow[t]{3}{*}{ Chronic diseases other than cancer } & Yes & 145 & 38.7 \\
\hline & No & 223 & 59.5 \\
\hline & Missing & 7 & 1.9 \\
\hline \multirow[t]{2}{*}{ Physical exercise } & Yes & 115 & 30.7 \\
\hline & No & 260 & 69.3 \\
\hline \multirow[t]{3}{*}{ Health insurance coverage } & Yes & 179 & 47.7 \\
\hline & No & 192 & 51.2 \\
\hline & Missing & 4 & 1.1 \\
\hline Received oral health information & Yes & 148 & 39.5 \\
\hline & No & 223 & 59.5 \\
\hline & Missing & 4 & I.I \\
\hline Newly diagnosed & Yes & 245 & 65.3 \\
\hline & No & 111 & 29.6 \\
\hline & Missing & 19 & 5.1 \\
\hline Depression & Yes & 168 & 44.8 \\
\hline & No & 207 & 55.2 \\
\hline Anxiety & Yes & 197 & 52.5 \\
\hline & No & 178 & 47.5 \\
\hline Stress & Yes & 160 & 42.7 \\
\hline & No & 215 & 57.3 \\
\hline Frequent tooth brushing ( $\geq 2$ times a day) & Yes & 149 & 40.3 \\
\hline & No & 221 & 59.7 \\
\hline Use dental floss & Yes & 70 & 18.8 \\
\hline & No & 302 & 81.2 \\
\hline
\end{tabular}

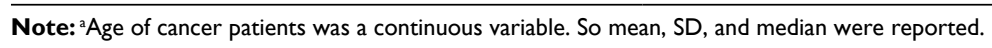


Table 2 The uRR and aRR, including their respective $95 \% \mathrm{Cls}$ and $p$-values for the association between number of oral health conditions experienced by the cancer patients and patient characteristics

\begin{tabular}{|c|c|c|c|c|c|c|c|}
\hline Characteristics & Category & uRR & $95 \% \mathrm{Cl}$ & $p$-value & aRR & $95 \% \mathrm{Cl}$ & $p$-value \\
\hline Age (years) & - & 0.99 & $(0.99-1.00)$ & 0.0640 & 1.00 & $(0.99-1.01)$ & 0.8348 \\
\hline \multirow[t]{2}{*}{ Gender } & Female & 1.35 & $(1.12-1.64)$ & $0.0021^{a}$ & 1.37 & $(1.05-1.78)$ & $0.0218^{\mathrm{a}}$ \\
\hline & Male & 1.00 & $(\operatorname{Ref})^{\mathrm{b}}$ & $(\operatorname{Ref})^{b}$ & 1.00 & $(\operatorname{Ref})^{b}$ & $(\operatorname{Ref})^{b}$ \\
\hline \multirow[t]{2}{*}{ Marital status } & Married & 0.93 & $(0.74-1.18)$ & 0.5669 & 1.07 & $(0.85-1.33)$ & 0.5676 \\
\hline & Not married & 1.00 & $(\operatorname{Ref})^{\mathrm{b}}$ & $(\operatorname{Ref})^{b}$ & 1.00 & $(\operatorname{Ref})^{\mathrm{b}}$ & $(\operatorname{Ref})^{b}$ \\
\hline \multirow[t]{2}{*}{ Education status } & Secondary or less & 1.01 & $(0.8 I-1.26)$ & 0.9274 & 1.00 & $(0.79-1.26)$ & 0.9808 \\
\hline & University or higher & 1.00 & $(\operatorname{Ref})^{b}$ & $(\operatorname{Ref})^{b}$ & 1.00 & $(\operatorname{Ref})^{b}$ & $(\operatorname{Ref})^{b}$ \\
\hline \multirow[t]{3}{*}{ Family income } & $<5,000$ & 1.69 & $(1.35-2.12)$ & $<\left.0.000\right|^{a}$ & 1.58 & $(1.23-2.04)$ & $0.0004^{a}$ \\
\hline & $5,000-10,000$ & 1.09 & $(0.85-I .4 I)$ & 0.4873 & 1.11 & $(0.87-I .4 I)$ & 0.4104 \\
\hline & $\geq 11,000$ & 1.00 & $(\operatorname{Ref})^{b}$ & $(\operatorname{Ref})^{b}$ & 1.00 & $(\operatorname{Ref})^{\mathrm{b}}$ & $(\operatorname{Ref})^{b}$ \\
\hline \multirow[t]{2}{*}{ Smoking status } & Yes & 1.01 & $(0.82-1.24)$ & 0.9394 & 1.29 & $(1.02-1.64)$ & $0.0338^{a}$ \\
\hline & No & 1.00 & $(\operatorname{Ref})^{b}$ & $(\operatorname{Ref})^{b}$ & 1.00 & $(\operatorname{Ref})^{b}$ & $(\operatorname{Ref})^{b}$ \\
\hline \multirow[t]{5}{*}{ Type of Cancer } & Breast cancer & 1.14 & $(0.92-1.42)$ & 0.2257 & 0.72 & $(0.56-0.93)$ & $0.0106^{\mathrm{a}}$ \\
\hline & Leukemia & 1.08 & $(0.68-1.73)$ & 0.7432 & 1.46 & $(0.94-2.26)$ & 0.0882 \\
\hline & Lung cancer & 1.34 & $(0.97-1.86)$ & 0.0795 & 1.04 & $(0.77-1.40)$ & 0.8111 \\
\hline & Lymph node & 1.23 & $(0.83-1.82)$ & 0.3085 & 1.28 & $(0.88-1.85)$ & 0.1994 \\
\hline & Colon cancer & 1.00 & $(\operatorname{Ref})^{b}$ & $(\operatorname{Ref})^{b}$ & 1.00 & $(\operatorname{Ref})^{b}$ & $(\operatorname{Ref})^{b}$ \\
\hline \multirow[t]{2}{*}{ Number of tumors } & Single tumor & 1.00 & $(0.82-I .2 I)$ & 0.9729 & 1.03 & $(0.87-1.23)$ & 0.7183 \\
\hline & Two or more & 1.00 & $(\operatorname{Ref})^{\mathrm{b}}$ & $(\operatorname{Ref})^{b}$ & 1.00 & $(\operatorname{Ref})^{\mathrm{b}}$ & $(\operatorname{Ref})^{\mathrm{b}}$ \\
\hline \multirow[t]{2}{*}{ Surgical therapy } & Yes & 1.17 & $(0.97-1.42)$ & 0.1035 & 1.18 & $(0.98-1.42)$ & 0.0861 \\
\hline & No & 1.00 & $(\operatorname{Ref})^{\mathrm{b}}$ & $(\operatorname{Ref})^{b}$ & 1.00 & $(\operatorname{Ref})^{b}$ & $(\operatorname{Ref})^{b}$ \\
\hline \multirow[t]{2}{*}{ Chemotherapy } & Yes & 0.97 & $(0.73-1.29)$ & 0.8396 & 1.16 & $(0.88-1.54)$ & 0.2983 \\
\hline & No & 1.00 & $(\operatorname{Ref})^{b}$ & $(\operatorname{Ref})^{b}$ & 1.00 & $(\operatorname{Ref})^{b}$ & $(\operatorname{Ref})^{b}$ \\
\hline \multirow[t]{2}{*}{ Radiation therapy } & Yes & 1.11 & $(0.91-1.34)$ & 0.2952 & 1.02 & $(0.86-1.23)$ & 0.7917 \\
\hline & No & 1.00 & $(\operatorname{Ref})^{b}$ & $(\operatorname{Ref})^{b}$ & 1.00 & $(\operatorname{Ref})^{\mathrm{b}}$ & $(\operatorname{Ref})^{b}$ \\
\hline \multirow[t]{2}{*}{ Immunotherapy } & Yes & 1.03 & $(0.84-1.25)$ & 0.7916 & 0.90 & $(0.75-1.08)$ & 0.2696 \\
\hline & No & 1.00 & $(\operatorname{Ref})^{b}$ & $(\operatorname{Ref})^{b}$ & 1.00 & $(\operatorname{Ref})^{\mathrm{b}}$ & $(\operatorname{Ref})^{b}$ \\
\hline Chronic diseases other than & Yes & 1.03 & $(0.85-1.25)$ & 0.7697 & 0.94 & $(0.78-1.13)$ & 0.5224 \\
\hline cancer & No & 1.00 & $(\operatorname{Ref})^{\mathrm{b}}$ & $(\operatorname{Ref})^{b}$ & 1.00 & $(\operatorname{Ref})^{b}$ & $(\operatorname{Ref})^{b}$ \\
\hline \multirow[t]{2}{*}{ Physical exercise } & Yes & 1.05 & $(0.85-1.29)$ & 0.6448 & 0.97 & $(0.79-1.18)$ & 0.7445 \\
\hline & No & 1.00 & $(\operatorname{Ref})^{\mathrm{b}}$ & $(\operatorname{Ref})^{b}$ & 1.00 & $(\operatorname{Ref})^{\mathrm{b}}$ & $(\operatorname{Ref})^{b}$ \\
\hline \multirow[t]{2}{*}{ Health insurance coverage } & Yes & 0.74 & $(0.6 \mathrm{I}-0.90)$ & $0.0020^{\mathrm{a}}$ & 0.90 & $(0.74-1.10)$ & 0.3152 \\
\hline & No & 1.00 & $(\operatorname{Ref})^{b}$ & $(\operatorname{Ref})^{b}$ & 1.00 & $(\operatorname{Ref})^{\mathrm{b}}$ & $(\operatorname{Ref})^{b}$ \\
\hline \multirow[t]{2}{*}{ Received oral health information } & Yes & 1.07 & $(0.88-1.29)$ & 0.5081 & 1.15 & $(0.95-1.39)$ & 0.1420 \\
\hline & No & 1.00 & $(\operatorname{Ref})^{b}$ & $(\operatorname{Ref})^{b}$ & 1.00 & $(\operatorname{Ref})^{b}$ & $(\operatorname{Ref})^{b}$ \\
\hline \multirow[t]{2}{*}{ Newly diagnosed } & Yes & 0.88 & $(0.72-1.08)$ & 0.2343 & 0.97 & $(0.80-1.16)$ & 0.7159 \\
\hline & No & 1.00 & $(\operatorname{Ref})^{b}$ & $(\operatorname{Ref})^{b}$ & 1.00 & $(\operatorname{Ref})^{b}$ & $(\operatorname{Ref})^{b}$ \\
\hline \multirow[t]{2}{*}{ Depression } & Yes & 1.78 & $(1.48-2.13)$ & $<0.000 \mathrm{I}^{\mathrm{a}}$ & 1.09 & $(0.88-1.36)$ & 0.4316 \\
\hline & No & 1.00 & $(\operatorname{Ref})^{b}$ & $(\operatorname{Ref})^{b}$ & 1.00 & $(\operatorname{Ref})^{b}$ & $(\operatorname{Ref})^{b}$ \\
\hline \multirow[t]{2}{*}{ Anxiety } & Yes & 2.22 & $(1.84-2.66)$ & $<\left.0.000\right|^{a}$ & 1.75 & $(1.36-2.24)$ & $<0.000 I^{a}$ \\
\hline & No & 1.00 & $(\operatorname{Ref})^{b}$ & $(\operatorname{Ref})^{\mathrm{b}}$ & 1.00 & $(\operatorname{Ref})^{\mathrm{b}}$ & $(\operatorname{Ref})^{\mathrm{b}}$ \\
\hline \multirow[t]{2}{*}{ Stress } & Yes & 1.87 & $(1.57-2.24)$ & $<\left.0.000\right|^{a}$ & 1.25 & $(1.00-1.55)$ & $0.0468^{\mathrm{a}}$ \\
\hline & No & 1.00 & $(\operatorname{Ref})^{b}$ & $(\operatorname{Ref})^{\mathrm{b}}$ & 1.00 & $(\operatorname{Ref})^{\mathrm{b}}$ & $(\operatorname{Ref})^{\mathrm{b}}$ \\
\hline Frequent tooth brushing & Yes & 1.03 & $(0.85-1.25)$ & 0.7816 & 1.01 & $(0.84-1.22)$ & 0.8785 \\
\hline ( $\geq 2$ times a day) & No & 1.00 & $(\operatorname{Ref})^{b}$ & $(\operatorname{Ref})^{b}$ & 1.00 & $(\operatorname{Ref})^{b}$ & $(\operatorname{Ref})^{b}$ \\
\hline \multirow[t]{2}{*}{ Use dental floss } & Yes & 1.00 & $(\operatorname{Ref})^{b}$ & $(\operatorname{Ref})^{b}$ & 1.00 & $(\operatorname{Ref})^{b}$ & $(\operatorname{Ref})^{b}$ \\
\hline & No & 1.00 & (0.77-1.29) & 0.9906 & 1.17 & $(0.93-1.49)$ & 0.1862 \\
\hline
\end{tabular}

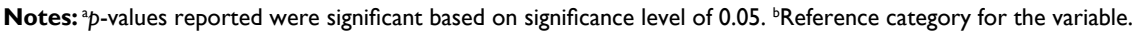

Abbreviations: uRR, unadjusted risk ratio; aRR, adjusted risk ratio.

the patients with no anxiety and stress, respectively. Multicollinearity was not evident among variables in our model. The goodness-of-fit chi-square test for the Poisson model was nonsignificant $(p=0.327)$, which indicated that Poisson regression model was appropriate for our study, and the results were not biased by overdispersion.

The expected mean number of oral health conditions among different cancer types, along with their respective $95 \%$ 
confidence levels, was comparatively illustrated in Figure 1. Patients diagnosed with breast cancer were expected to have experienced $1.6(95 \% \mathrm{CI}: 1.2-2.1)$ oral health complaints on average in comparison with the next highest number of 2.2 (95\% CI: 1.8-2.6) expected conditions observed in colon cancer patients.

\section{Discussion}

Our study demonstrated a significant burden (86.1\%) of oral health problems experienced by cancer patients in Saudi Arabia. For the first time in the nation, we identified that female sex, low income, smoking, suffering from breast cancer, suffering from anxiety, and stress were key determinants of oral health problems in cancer patients. Our results have direct implications at improving the care of cancer patients by highlighting the need to incorporate oral health component in management of cancer patients.

The prevalence of oral health problems experienced by cancer patients in our study was considerably higher than
$28.1 \%$ reported in a recent systematic review, ${ }^{7}$ indicating the severity of this problem in Saudi Arabia. Previous studies also reported wide-ranging prevalence measures for therapy-induced oral complications ranging from $10 \%$ for adjuvant chemotherapy to $91 \%-100 \%$ for patients treated with radiation therapy. ${ }^{9-11,18}$ In contrast, no association was observed between various therapeutic modalities and oral health in our study possibly due to time elapsed since therapy. Therefore, future studies should address the relevance of timing of therapy on oral health problems in Saudi Arabia. As the burden of oral health conditions in cancer patients was established, it is essential to incorporate oral health management in routine cancer therapy protocols to mitigate the risk of adverse oral health on quality of life.

Female cancer patients in our study experienced poor oral health consistent with historical evidence. ${ }^{19}$ Similar trend was observed in general population, where women experienced a higher prevalence of oral lesions (58\%) than men $(42.3 \%) .{ }^{20}$ The preferred mode of dissemination of health education

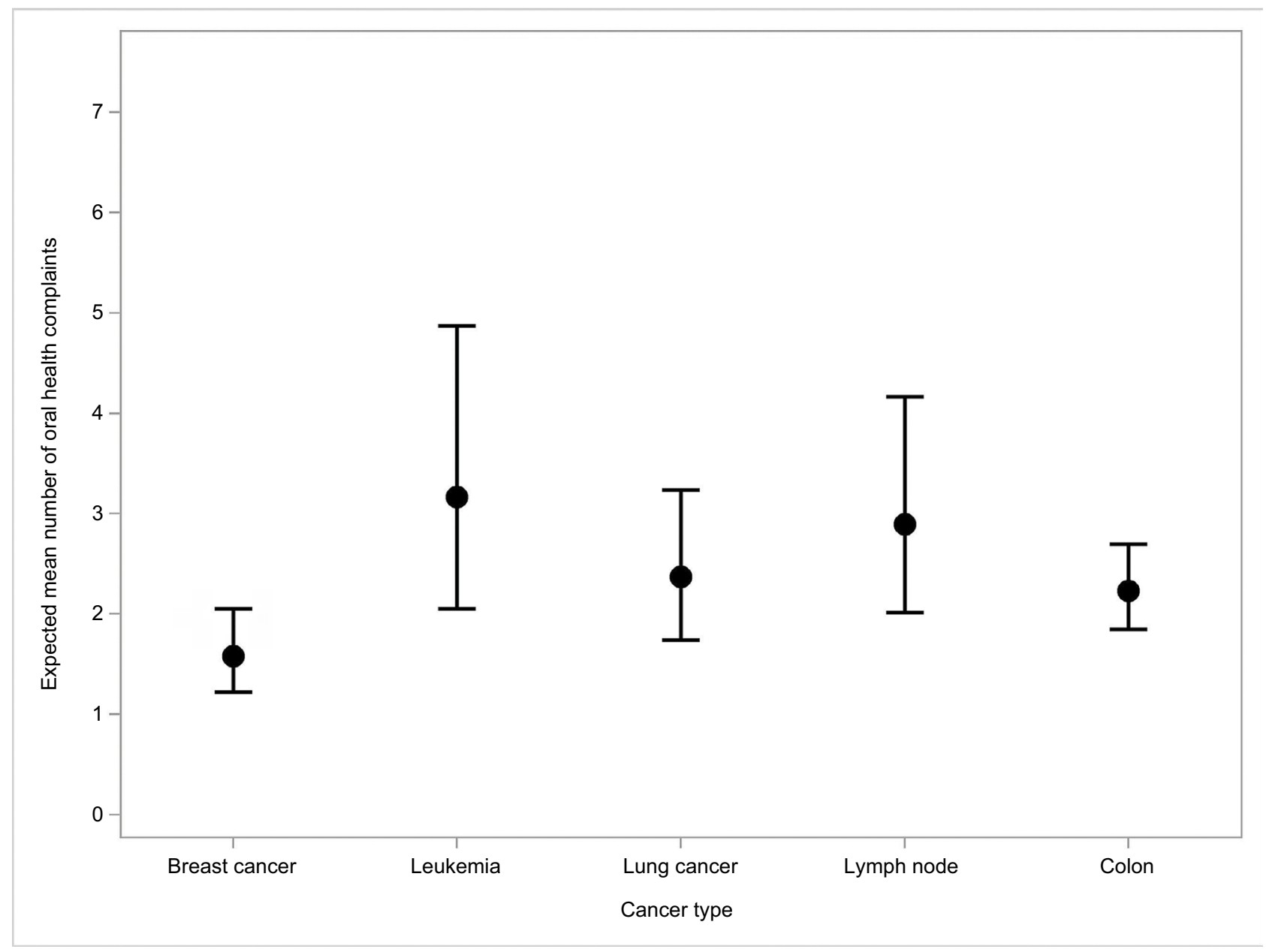

Figure I Comparative illustration of expected mean number of oral health complaints by cancer type. 
varied between men (eg, one-to-one method) and women (eg, one-to-one and group education); ${ }^{21}$ therefore, oncologists and other healthcare providers should tailor their oral health education programs to fulfil the needs of their patients.

In our study, low family income was among key factors associated with oral health in cancer patients, consistent with the literary evidence that linked poverty to adverse oral health in general population. ${ }^{22}$ Low-income patients encounter significant problems in accessing dental care ${ }^{23}$ and receiving adequate information on oral care from oncologists further compounding the problem. ${ }^{24}$ Therefore, care providers should emphasize the benefits of basic oral care to economically backward cancer patients and recommend or refer them to specialized dental consultation.

Our results were consistent with prior literature that identified the negative impact of smoking on oral health. ${ }^{25}$ It is interesting to note that the 1.3-fold higher risk of oral-facial pain observed in a prior study ${ }^{25}$ was consistent with the risk observed for oral conditions experienced in our population of smokers. Smokers have consistently scored poorly (24\%) on the self-reported oral health status compared to nonsmokers (11\%), ${ }^{25}$ emphasizing the need to rigorously pursue smoking cessation efforts in cancer patients.

It is interesting to note that the expected number of oral health problems was significantly lower in breast cancer patients compared with colon cancer patients in our study. Similarly, a recent study conducted in the USA reported 1.6 mouth sores on average among breast cancer patients. ${ }^{26}$ In another study that collectively analyzed common cancerrelated and treatment-related symptoms, including xerostomia and pain, the percentage of moderate to severe symptoms reported by breast cancer patients was consistently lower than those reported by colorectal and lung cancer patients as noted in our study. ${ }^{27}$ Future studies could focus on identifying possible mechanisms that influenced better oral health experience in breast cancer patients.

Our study identified significant burden of anxiety among cancer patients in Saudi Arabia. We also observed a strong relationship between anxiety and adverse oral health in cancer patients; a 1.7-fold higher number of oral complaints was expected among anxious patients. Our results were consistent with prior studies that linked anxiety to oral health complaints, such as xerostomia in cancer patients ${ }^{28}$ and toothache in health sciences students. ${ }^{29}$ It was demonstrated that anxious patients tend to avoid dental care, ${ }^{30}$ therefore, cancer therapists should consider treating anxiety in patients to indirectly enhance oral health.
Stress was known to affect oral health in general ${ }^{31}$ and was specifically linked to oral ulcers, ${ }^{32}$ oral pain, gingivitis, and plaques in prior studies. ${ }^{33}$ Our study revealed a significant positive association between stress and oral health in cancer patients, thereby highlighting the need to prioritize management of stress and anxiety in Saudi cancer population.

Our study was the first in Saudi Arabia that highlighted the burden of adverse oral health and identified associated factors for oral health problems in cancer patients. In addition, this study provided baseline data that are essential to evaluate the progress of oral health in cancer patients. Our study contributed to the knowledge of risk factors of oral health in cancer patients that could have implications worldwide, and more specifically to Gulf region. The approach of collectively analyzing oral health complaints among cancer patients would benefit researchers and healthcare practitioners in better understanding the determinants of overall oral health rather than a specific condition, which in turn could lead to greater adoption of specialized oral care in routine cancer management protocols.

However, certain limitations of this study warrant caution in interpreting the results. Mainly, cross-sectional nature of this study does not allow drawing any causal inferences. However, owing to the dearth of literature in this area, our results could direct future studies by allowing hypothesis generation and providing useful information to target vulnerable populations. As self-reporting was used to collect patient information, our study was prone to recall bias; however, we expect that the effect of such a bias to be minimal owing to routine and recurrent nature of information collected. Furthermore, our questionnaire tailored to account for cultural sensitivities of Saudi cancer patients may not be suitable for wider adoption without further validation. Although our study based on a single city hospital in Saudi Arabia limits generalizability, we would expect the findings to be relevant to general population owing to cultural similarities of the Saudi populace and wide catchment area of the tertiary hospital where the sample was obtained.

\section{Conclusion}

Overall, our study determined significant burden of oral health problems in cancer patients and also identified several associated factors for adverse oral health. The significant relationship between adverse oral health conditions and females, low economic groups and smokers warrant improvement of health education programs and patient counseling methods targeting these patients. Further investigation of lower risk 
observed uniquely in breast cancer patients is warranted to uncover underlying mechanisms that influence oral health. Healthcare practitioners should aim at incorporating detection and management of anxiety and stress in cancer patients who have profound influence on oral health.

\section{Acknowledgments}

The authors would like to thank all participants in the study and King Abdullah International Medical Research Center for approving the project and providing funding to cover publication fees.

\section{Disclosure}

The authors report no conflicts of interest in this work. Coauthors, Aisha Taha Qureshey and Eiman Taha Qureshey, are sisters.

\section{References}

1. American Cancer Society. The Global Cancer Burden. Atlanta: American Cancer Society, Inc; 2018. Available from: https://www.cancer. org/health-care-professionals/our-global-health-work/global-cancerburden.html. Accessed January 30, 2018.

2. Torre LA, Bray F, Siegel RL, Ferlay J, Lortet-Tieulent J, Jemal A. Global cancer statistics, 2012. CA Cancer J Clin. 2015;65(2):87-108.

3. Saudi Health Council. Cancer Incidence Report Saudi Arabia 2014. Kingdom of Saudi Arabia: Saudi Health Council; 2017. Available from: http://www.chs.gov.sa/En/HealthRecords/CancerRegistry/Pages/ CancerRegistryRecords.aspx. Accessed January 30, 2018.

4. Ahmed AE, Almuzaini AS, Alsadhan MA, et al. Health-related predictors of quality of life in cancer patients in Saudi Arabia. J Cancer Educ. 2017 Epub Mar 7.

5. Wong HM. Oral complications and management strategies for patients undergoing cancer therapy. ScientificWorldJournal. 2014;2014:581795.

6. Epstein JB, Thariat J, Bensadoun RJ, et al. Oral complications of cancer and cancer therapy: from cancer treatment to survivorship. CA Cancer J Clin. 2012;62(6):400-422.

7. Hong $\mathrm{CH}$, Napenas JJ, Hodgson BD, et al. A systematic review of dental disease in patients undergoing cancer therapy. Support Care Cancer. 2010;18(8):1007-1021.

8. Joshi VK. Dental treatment planning and management for the mouth cancer patient. Oral Oncol. 2010;46(6):475-479.

9. Raber-Durlacher JE, Barasch A, Peterson DE, Lalla RV, Schubert MM, Fibbe WE. Oral complications and management considerations in patients treated with high-dose chemotherapy. Support Cancer Ther. 2004;1(4):219-229.

10. Sonis ST. Oral complications of cancer chemotherapy. In: De Vita VT, Hellmann S, Rosenberg SA, editors. Cancer: Principles and Practice of Oncology. Philadelphia: JB Lippincott; 1993:2014-2022.

11. Maria OM, Eliopoulos N, Muanza T. Radiation-induced oral mucositis. Front Oncol. 2017;7:89.

12. Schweiger JW. Oral complications following radiation therapy: a fiveyear retrospective report. $J$ Prosthet Dent. 1987;58(1):78-82.

13. Mandel ID. The role of saliva in maintaining oral homeostasis. J Am Dent Assoc. 1989;119(2):298-304.
14. Chambers MS, Toth BB, Martin JW, Fleming TJ, Lemon JC. Oral and dental management of the cancer patient: prevention and treatment of complications. Support Care Cancer. 1995;3(3):168-175.

15. Miller M, Kearney N. Oral care for patients with cancer: a review of the literature. Cancer Nurs. 2001;24(4):241-254.

16. Barker GJ, Epstein JB, Williams KB, Gorsky M, Raber-Durlacher JE. Current practice and knowledge of oral care for cancer patients: a survey of supportive health care providers. Support Care Cancer. 2005;13(1):32-41.

17. Lovibond SH, Lovibond PF. Manual for the Depression, Anxiety and Stress Scales (DASS). 2nd ed. Sydney: Psychology Foundation of Australia; 1995.

18. Elting LS, Cooksley CD, Chambers MS, Garden AS. Risk, outcomes, and costs of radiation-induced oral mucositis among patients with head-and-neck malignancies. Int J Radiat Oncol Biol Phys. 2007;68(4): $1110-1120$.

19. Lukacs JR. Sex differences in dental caries experience: clinical evidence, complex etiology. Clin Oral Investig. 2011;15(5):649-656.

20. Al-Mobeeriek A, AlDosari AM. Prevalence of oral lesions among Saudi dental patients. Ann Saudi Med. 2009;29(5):365-368.

21. Al-Khashan HI, Almulla NA, Galil SA, Rabbulnabi AA, Mishriky AM. Gender differences in health education needs and preferences of Saudis attending Riyadh Military Hospital in the Kingdom of Saudi Arabia. J Family Community Med. 2012;19(3):172-177.

22. Dye BA, Thornton-Evans G. Trends in oral health by poverty status as measured by Healthy People 2010 objectives. Public Health Rep. 2010;125(6):817-830.

23. Ontario Public Health Association. Position Statement on Poverty and Children's Oral Health. Toronto: Ontario Public Health Association; 2005. Available form: http://www.opha.on.ca/getmedia/201ddb04-8ca7484d-aaaa-fbe8c588c593/2005-02_pp.pdf.aspx?ext=.pdf. Accessed January 30, 2018.

24. Howard JR, Ramirez J, LiY, Gany F. Dental care access for low-income and immigrant cancer patients in New York City. J Community Health. 2015;40(1):110-115.

25. Millar WJ, Locker D. Smoking and oral health status. J Can Dent Assoc. 2007;73(2):155.

26. Taichman LS, Van Poznak CH, Inglehart MR. Oral health-related concerns, behavior, and communication with health care providers of patients with breast cancer: impact of different treatments. Spec Care Dentist. 2018;38(1):36-45.

27. Cleeland CS, Zhao F, Chang VT, et al. The symptom burden of cancer: Evidence for a core set of cancer-related and treatment-related symptoms from the Eastern Cooperative Oncology Group Symptom Outcomes and Practice Patterns study. Cancer. 2013;119(24):4333-4340.

28. Wu YS, Lin PY, Chien CY, et al. Anxiety and depression in patients with head and neck cancer: 6-month follow-up study. Neuropsychiatr Dis Treat. 2016;12:1029-1036.

29. Marques-Vidal P, Milagre V. Are oral health status and care associated with anxiety and depression? A study of Portuguese health science students. J Public Health Dent. 2006;66(1):64-66.

30. Nicolas E, Collado V, Faulks D, Bullier B, Hennequin M. A national cross-sectional survey of dental anxiety in the French adult population. BMC Oral Health. 2007;7:12.

31. Vasiliou A, Shankardass K, Nisenbaum R, Quinonez C. Current stress and poor oral health. BMC Oral Health. 2016;16(1):88.

32. Loo WT, Liu Q, Yip MC, et al. Status of oral ulcerative mucositis and biomarkers to monitor posttraumatic stress disorder effects in breast cancer patients. Int J Biol Markers. 2013;28(2):168-173.

33. Deinzer R, Granrath N, Spahl M, Linz S, Waschul B, Herforth A. Stress, oral health behaviour and clinical outcome. Br J Health Psychol. 2005;10(Pt 2):269-283. 
Cancer Management and Research

\section{Publish your work in this journal}

Cancer Management and Research is an international, peer-reviewed open access journal focusing on cancer research and the optimal use of preventative and integrated treatment interventions to achieve improved outcomes, enhanced survival and quality of life for the cancer patient.

The manuscript management system is completely online and includes

Submit your manuscript here: https://www.dovepress.com/cancer-management-and-research-journal

a very quick and fair peer-review system, which is all easy to use. Visit $\mathrm{http}: / / \mathrm{www}$.dovepress.com/testimonials.php to read real quotes from published authors. 